\title{
Bivariate Beta Exponential Distributions
}

\author{
Mervat K. Abd Elaal ${ }^{1,2}$ \\ 1 Statistics Department, Faculty of Sciences King Abdulaziz University Jeddah, Kingdom of Saudi Arabia \\ 2 Statistics Department, Faculty of Commerce Al-Azhar University, Girls Branch Cairo, Egypt
}

\begin{abstract}
The exponential distribution is perhaps the most widely applied statistical distribution in reliability. Anew continuous bivariate distribution called the bivariate beta-exponential distribution (BBE) that extends the bivariate exponential distribution are proposed. We introduce a new bivariate beta-exponential distributions $(B B E)$ based on some types of copulas. Parametric and semiparametric methods are used to estimate the parameters of the models. Finally, Simulation is studied to illustrate methods of inference discussed and examine the satisfactory performance of the proposed distributions.
\end{abstract}

Key words: Beta exponential distribution, beta $G$ distribution, bivariate beta exponential distributions; Maximum likelihood method; copula;

\section{Introduction}

The exponential distribution is a popular distribution the most widely used and applied for analyzing lifetime data and for problems in reliability.

The exponential distribution is a popular distribution widely used for analyzing lifetime data. The exponential distribution is perhaps the most widely applied statistical distribution for problems in reliability. In this aim, we consider a generalization referred to as the beta exponential distribution generated from the logit of a beta random variable. We work with the beta exponential (BE) distribution because of the wide applicability of the exponential distribution and the fact that it extends some recent developed distributions. An application is illustrated to a real data set with the hope that it will attract more applications in reliability, biology and other areas of research.

Eugene et al. (2002) introduced the beta distribution as a generator to suggest the so-called family of beta $\mathrm{G}$ distributions. The cumulative distribution function (c.d.f.) of a beta- $\mathrm{G}$ random variable $\mathrm{X}$ is defined as

$\mathrm{F}(x)=I_{G(x)}(a, b)=\frac{1}{B(a, b)} \int_{0}^{G(x)} w^{a-1}(1-w)^{b-1} d w$,

for $\mathrm{G}(\mathrm{x})$ is the cdf of any random variable, $\mathrm{a}>0$ and $\mathrm{b}>0$, where $I_{y}(a, b)=B_{y}(a, b) / B(a, b)$ denotes the incomplete beta function ratio, and $B_{y}(a, b)=\int_{0}^{y} w^{a-1}(1-w)^{b-1} d w$ denotes the incomplete beta function. The p.d.f. corresponding to the beta-G distribution in (1) is given by

$$
f(x)=\frac{1}{B(a, b)} G^{a-1}(x)(1-G(x))^{b-1} g(x) .
$$

where $\mathrm{g}(\mathrm{x})=\mathrm{dG}(\mathrm{x}) / \mathrm{dx}$ is the pdf of the parent distribution. The pdf $\mathrm{f}(\mathrm{x})$ will be most tractable when the functions $\mathrm{G}(\mathrm{x})$ and $\mathrm{g}(\mathrm{x})$ have simple analytic expressions.

This family of distributions is a generalization of the distributions of order statistics for the random variable X with cdf F(x) as pointed out by Eugene, et al. (2002) and Jones (2004). Since the paper by Eugene et al. (2002), many beta-G distributions have been studied in the literature including the beta-Gumbel distribution by Nadarajah and Kotz (2004), beta exponential distribution by Nadarajah and Kotz (2006), beta-Weibull distribution by Famoye et al.(2005) and Cordeiro et al., (2011).

For more details, see, also, the beta-Pareto distribution by Akinsete, et al. (2008), beta modified Weibull distribution by Silva et al.(2010), beta generalized half-normal distribution by Pescim et al., (2010), And ,also, the beta Burr XII distribution by Paranaiba, et al., (2011), beta extended Weibull distribution by Cordeiro, et al.(2012), beta exponentiated Weibull by Cordeiro et al.(2013),beta-lindley distribution by Merovci and Sharma (2014), beta Burr type X distribution by Merovci et al.,(2016).

Eugene et al. (2002) introduced the beta normal distribution by taking $G(x)$ in (1) to be the cdf of the normal distribution. Nadarajah and Kotz (2004) introduced the beta Gumbel (BG) distribution by taking G(x) to be the cdf of the Gumbel distribution. Also, Nadarajah and Kotz (2006) studied the BE distribution and obtained the moment generating function, the asymptotic distribution of the extreme order statistics and discussed the maximum likelihood estimation. For more details, see Azzalini(1985), Alexander, et al., (2012),Nadarajah and Rocha (2016a), Nadarajah and Rocha (2016b), Alzaatreh et al., (2013), Aljarrah et al., (2014), Nadarajah, et al., (2015).

Beta exponential distribution used effectively in different lifetime applications. Nadarajah and Kotz (2006) first introduced it. 
We now study the BE distribution by taking $\mathrm{G}(\mathrm{x})$ in $(1)$ to be the cdf of the exponential (E) distribution. Then, the beta exponential (BE) distribution with three parameters $\alpha>0, a>0$ and $b>0$ with the following Cdf and the pdf, respectively,

$$
F(x)=\frac{1}{B(a, b)} \int_{0}^{1-\exp (-\alpha x)} w^{a-1}(1-w)^{b-1} d w
$$

The simple formula for the cdf of BE distribution if a, bare real integer given by $F(x)=\frac{[1-\exp (-\alpha x)]^{a}}{\Gamma(a)} \sum_{j=0}^{b-1} \frac{\Gamma(a+j)}{j !}\{\exp (-j \alpha x)\}$,

And, the pdf given by

$$
f(x)=\frac{\alpha}{B(a, b)}[1-\exp (-\alpha x)]^{a-1} \exp (-b \alpha x), x>0, \alpha, a, b>0 .
$$

And the hazard rate function given by

$$
h(x)=\frac{\alpha \exp (-b \alpha x)[1-\exp (-\alpha x)]^{a-1}}{B(a, b) I_{\exp (-\alpha x)}(a, b)} .
$$

The moment generating function (mgf) of the BE distribution if $b>2$ is integer is given by

$$
M(t)=\frac{1}{B(a, b)} \sum_{j=0}^{b-1}\left(\begin{array}{c}
b-1 \\
j
\end{array}\right)(-1)^{j} B(1-t / \alpha, a+j) .
$$

The simple formula for the mgf of BE distribution is given by

$$
M(t)=\frac{B(b-t / \alpha, a)}{B(a, b)} \text {. }
$$

The $\mathrm{r}$ th moment of the BE distribution if $\mathrm{b}$ is integer can be obtain from

$\mu_{r}^{\prime}=\frac{\Gamma(b)}{\alpha^{r} B(a, b)} \sum_{j=0}^{b-1}\left(\begin{array}{c}b-1 \\ j\end{array}\right)(-1)^{j+r}\left|\frac{d^{r} B(p,(a+j))}{d p^{r}}\right|_{p=1}$.

The first four moments of the BE distribution if $b>0$ is integer are obtain, respectively,

Where $c_{j}, d_{j}, e_{j}$ and $f_{j}$ are given by

$$
\begin{aligned}
& \mu_{1}^{\prime}=\frac{\Gamma(a+b)}{\alpha \Gamma(a)} \sum_{j=0}^{b-1}\left(\begin{array}{c}
b-1 \\
j
\end{array}\right) \frac{(-1)^{j}}{a+j} c_{j}, \\
& \mu_{2}^{\prime}=\frac{\Gamma(a+b)}{\alpha^{2} \Gamma(a)} \sum_{j=0}^{b-1}\left(\begin{array}{c}
b-1 \\
j
\end{array}\right) \frac{(-1)^{j}}{a+j} d_{j}, \\
& \mu_{3}^{\prime}=\frac{\Gamma(a+b)}{\alpha^{3} \Gamma(a)} \sum_{j=0}^{b-1}\left(\begin{array}{c}
b-1 \\
j
\end{array}\right) \frac{(-1)^{j}}{a+j} e_{j}, \\
& \mu_{4}=\frac{\Gamma(a+b)}{\alpha^{4} \Gamma(a)} \sum_{j=0}^{b-1}\left(\begin{array}{c}
b-1 \\
j
\end{array}\right) \frac{(-1)^{j}}{a+j} f_{j},
\end{aligned}
$$

$$
\begin{aligned}
& c_{j}=\psi(a+j+1)+\psi(1), \\
& d_{j}=c_{j}^{2}+\hat{\psi}(1)-\psi(a+j+1)+\psi(1), \\
& e_{j}=-c_{j}\left[c_{j}^{2}+3\{\dot{\psi}(1)-\dot{\psi}(a+j+1)\}\right]+\dot{\psi}(1)-\dot{\psi}(a+j+1), \\
& f_{j}=\left\{c_{j}^{2}+\dot{\psi}(1)-\dot{\psi}(a+j+1)\right\}\left[c_{j}^{2}+3\{\dot{\psi}(1)-\dot{\psi}(a+j+1)\}\right]+2 c_{j}^{2}\{\dot{\psi}(1)-\dot{\psi}(a+j+1)\}-4 c_{j}\{\dot{\psi}(1) \\
& -\hat{\psi}(a+j+1)\}
\end{aligned}
$$

The BE distribution contains as special cases three well-known distributions. For example, it simplifies to the $\mathrm{BW}$ distribution when. If $\alpha=1$, the $\mathrm{BE}$ distribution becomes the beta standard exponential (BSE) distribution, If $\mathrm{b}=1$, the $\mathrm{BE}$ distribution becomes the EE distribution, The Exponential distribution is clearly a special case for $\mathrm{a}=\mathrm{b}=1$.

Copulas are a general tool to construct multivariate distributions and to find dependence structure between random variables. However, the concept of copula is popular in multivariate analyses. In this aim, we show that copulas can be important used to solve many statistical problems. Stated that any multivariate distribution can be disintegrated to a copula and its continues marginal.

The Gaussian copula gives the following form

$$
C(u, v)=\varphi_{\Sigma}\left(\varphi^{-1}(u), \varphi^{-1}(v)\right)
$$

where $\varphi_{\Sigma}$ denotes the distribution function of a bivariate standard normal random variable and $\varphi^{-1}$ represents its inverse.

The Farlie-Gumbel-Morgensten copula (FGM) takes the following form

$$
C(u, v)=u v[1+\theta(1-\mathrm{u})(1-\mathrm{v})]
$$

where $u$ and $v \in I$, and $\theta \in[-1,1]$ is a dependence parameter. 
Although the FGM copula family is tractable mathematically, it does not model high dependences. The range of the dependence measures Kendall's tau $\tau$ and Spearman's rho $\rho$ are $\tau \in[-0.222,0.222]$ and $\rho \in[-0.333,0.333]$ respectively.

The Plackett copula takes the following form

$$
\mathrm{C}(\mathrm{u}, \mathrm{v})=\frac{1+(\theta-1)(u+v)}{2(\theta-1)}-\frac{\sqrt{[1+(\theta-1)(u+v)]^{2}-4 u v \theta(\theta-1)}}{2(\theta-1)},
$$

Where $\theta \in(0, \infty)$. The correlation measure Spearman's rho is $\rho=\frac{\theta+1}{\theta-1}-\frac{2 \theta \log (\theta)}{(\theta-1)^{2}}$. There is no closed expression in $\theta$ for the correlation measure Kendall's tau.

Several multivariate and bivariate lifetime distributions are derived using copula functions such as Johnson, et al.(1992), Nelsen(1999), Adham and Walker, (2001), Trivedi and Zimmer, (2005), Adham, et al. (2009), Kundu, et al.(2009), Kunduet al. (2010), Kundu and Gupta, (2011), Ateya and Al-Alazwari, (2013), Sarabia et al. (2014), Abd Elaal et al.(2016), Adham et al. (2016), and Abd Elaal et al.(2017).

The main article of this article is to introduce bivariate beta exponential (BBE) models based on most used copula functions in the literature as the Gaussian, Frank, Clayton, and Farlie-Gumbel-Morgensten (FGM) and suggest which of them is more suitable. In addition, the performance of the proposed BBE will be examined using a real data example.

The contents of this aim are as follows. Section 2 introduce three new bivariate beta exponential (BBE) models based on different copula functions. Parametric and semiparametric methods are used to estimate the parameters of BBE models in Section 3. In Section 4, goodness of fit test for the three models of bivariate beta exponential (BBE) models computed to check the flexibility of different models based on different copula functions. Finally, Simulation is studied to illustrate the performance of the suggested bivariate models and compare each one to other bivariate models in Section 5.

\section{Bivariate BE Distributions Based On Copulas}

For the bivariate case, copulas are used to link two marginal distributions with joint distribution such that for every bivariate distribution function $F\left(x_{1}, x_{2}\right)$ with continuous marginal $F\left(x_{1}\right), F\left(x_{2}\right)$, there exist a unique copula function $\mathrm{C}$ as follows

$$
F\left(x_{1}, x_{2}\right)=C\left\{F\left(x_{1}\right), F\left(x_{2}\right)\right\}, \quad\left(x_{1}, x_{2}\right) \in(-\infty, \infty) X(-\infty, \infty)
$$

The density function of bivariate distribution gives as

$$
f\left(x_{1}, x_{2}\right)=f_{1}\left(x_{1}\right) f_{2}\left(x_{2}\right) c\left(F_{1}\left(x_{1}\right), F_{2}\left(x_{2}\right),\right.
$$

Where $c\left(F_{1}\left(x_{1}\right), F_{2}\left(x_{2}\right)\right.$ is the density function of copula.

see (Nelsen, 1999). Several copula functions can be used to construct BBE distributions with BE marginals given by (4). In this article, we will applied the Gaussian, Farlie-Gumbel-Morgensten and Plackett copulas to construct BBE distributions.

The joint PDF of $X_{1}$ and $X_{2}$ based on Gaussian copula becomes

$$
f\left(x_{1}, x_{2}\right)=f_{1}\left(x_{1}\right) f_{2}\left(x_{2}\right)\left\{\frac{1}{\sqrt{1-\rho^{2}}}\left(\exp \left[\frac{-\rho}{2\left(1-\rho^{2}\right)}\left\{\rho\left(z_{1}^{2}+z_{2}^{2}\right)-2 z_{1} z_{2}\right\}\right]\right)\right\} \text {. }
$$

where $\rho \in[-1,1]$ is a dependence parameter.

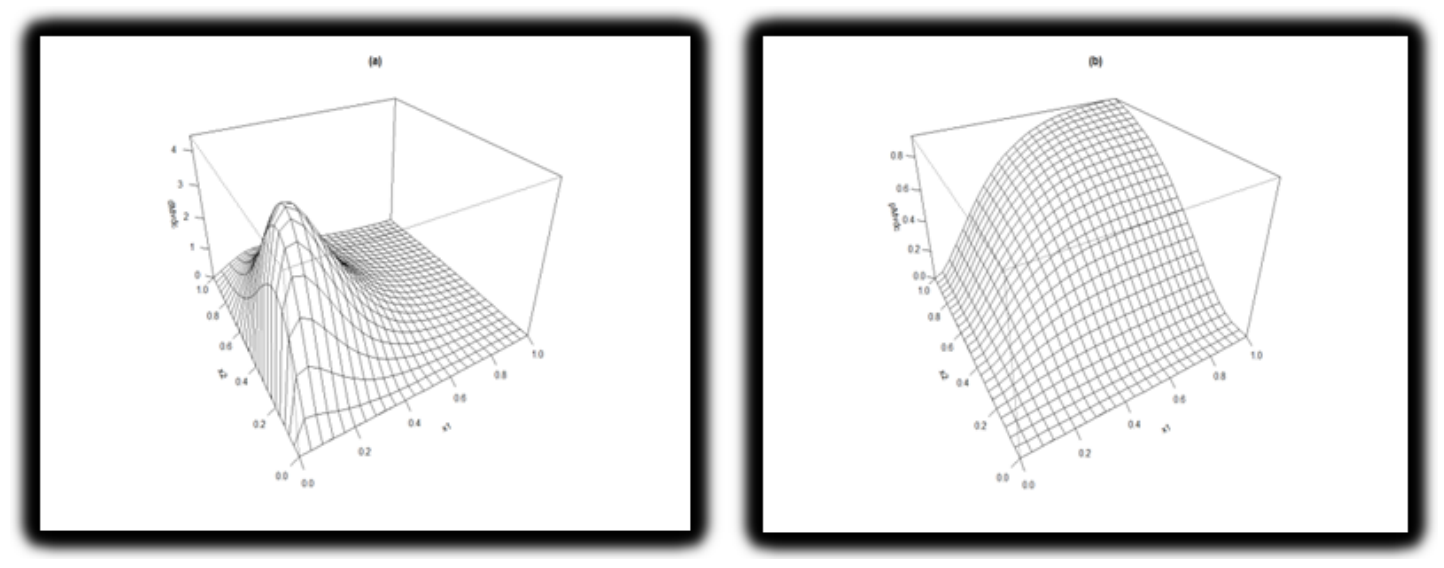

Figure (1): Plots the PDF and Cdf of the BBE based on Gaussian copula 


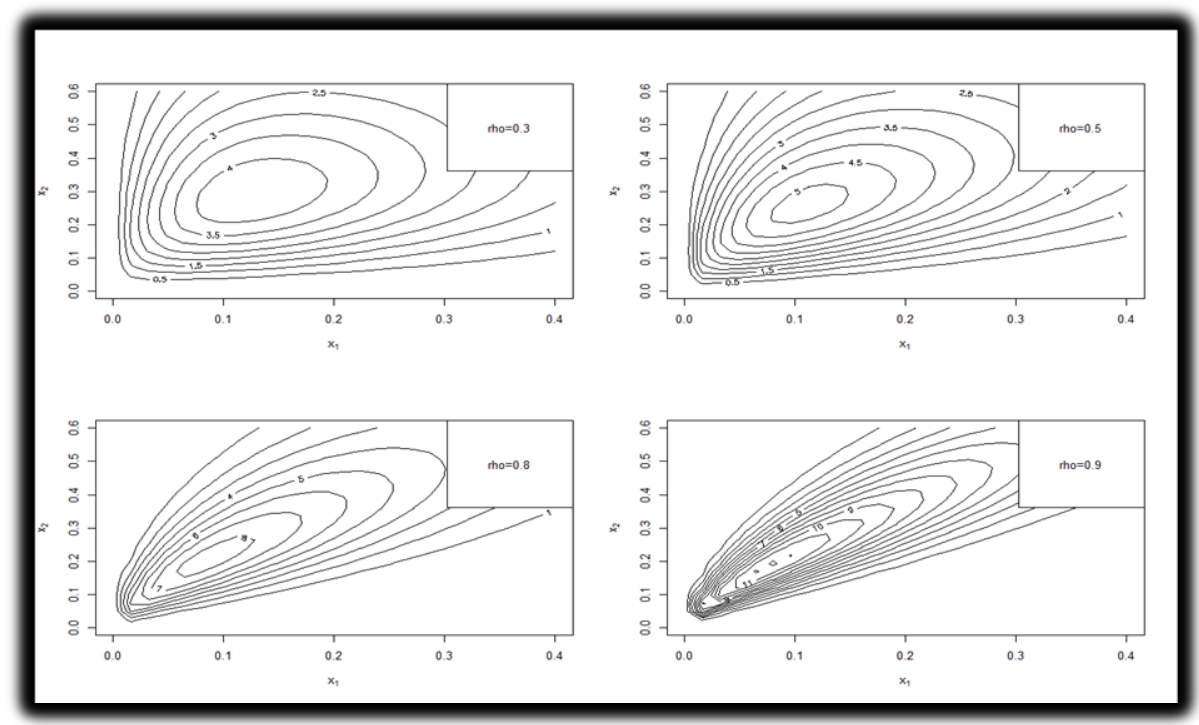

Figure (2): Contour plots of BBEbased on Gaussian copula for different values of $\theta$.

The joint PDF of $X_{1}$ and $X_{2}$ based on Farlie-Gumbel-Morgensten copula becomes $f\left(x_{1}, x_{2}\right)=f_{1}\left(x_{1}\right) f_{2}\left(x_{2}\right)[1+\theta(1-2 \mathrm{u})(1-2 \mathrm{v})]$. where $\mathrm{u}$ and $\mathrm{v} \in \mathrm{I}$, and $\theta \in[-1,1]$ is a dependence parameter.
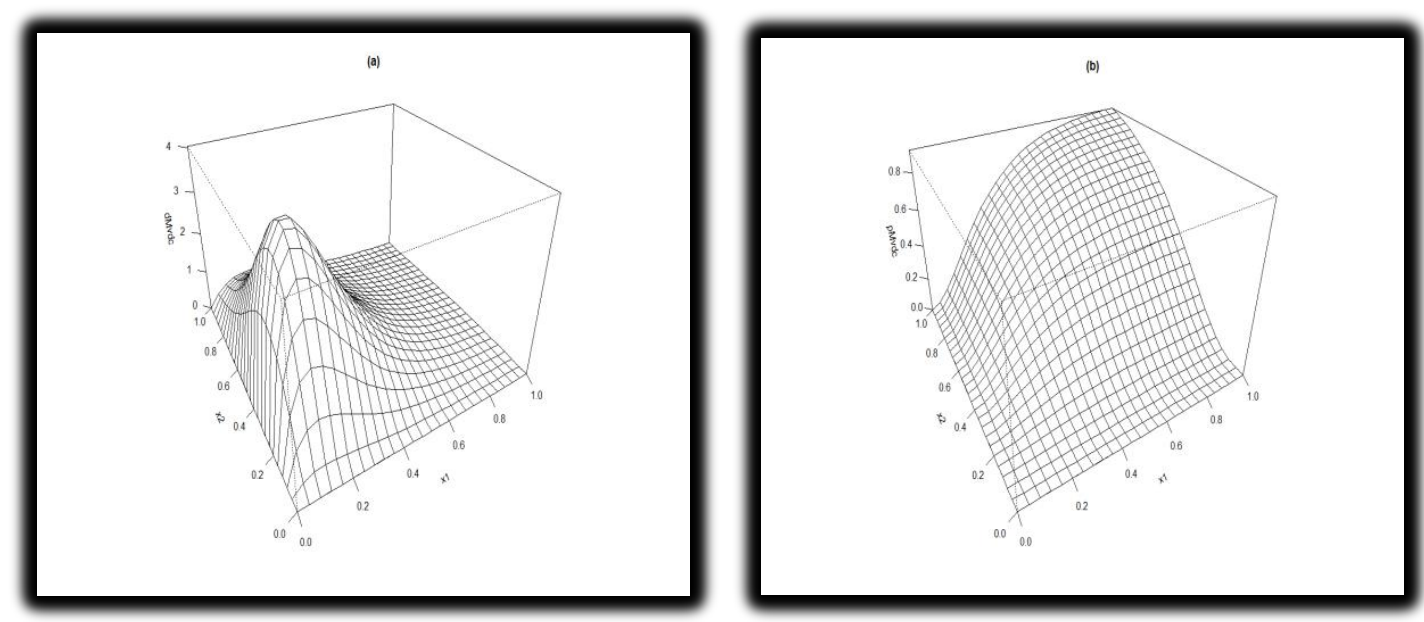

Figure (3): Plots the PDF and Cdf of the BBE based on FGM copula

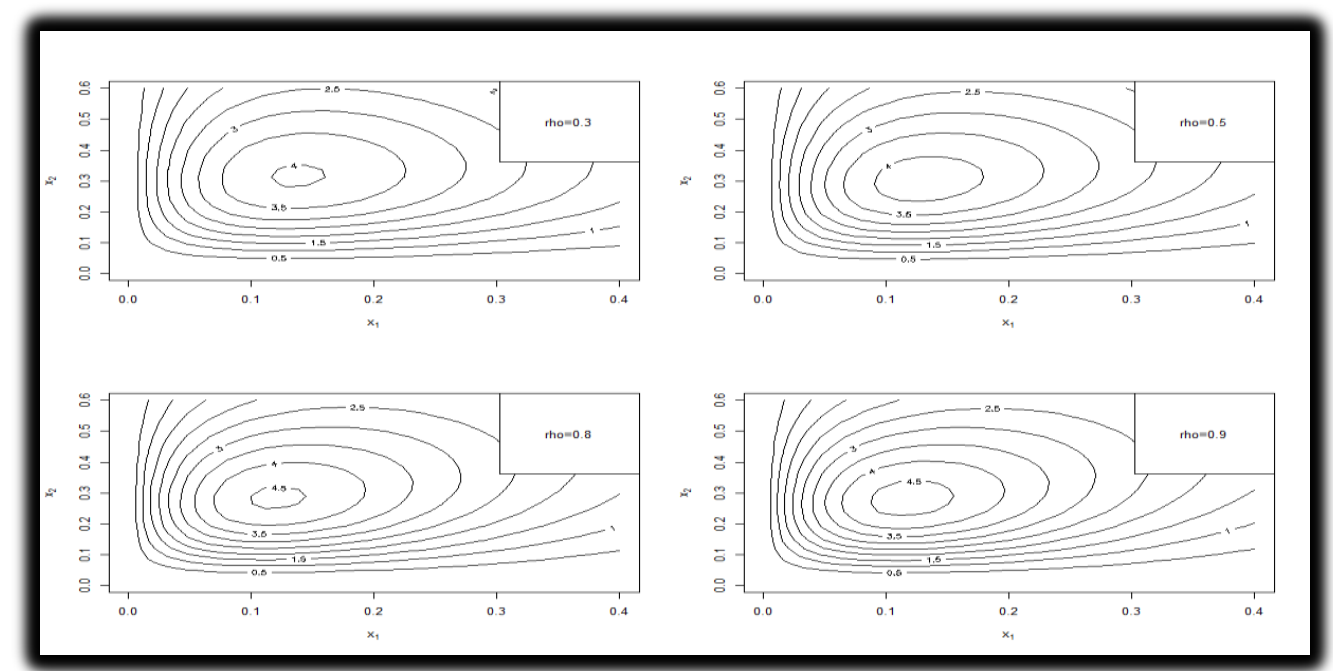

Figure (4): Contour plots of BBEbased on FGM copula for different values of $\theta$. 
The joint PDF of $X_{1}$ and $X_{2}$ based on Plackett copula becomes

$$
f\left(x_{1}, x_{2}\right)=f_{1}\left(x_{1}\right) f_{2}\left(x_{2}\right) \frac{\theta[1+(\mathrm{u}-2 \mathrm{uv}+\mathrm{v})(\theta-1)]}{\left([1+(\theta-1)(\mathrm{u}+\mathrm{v})]^{2}-4 \mathrm{uv} \theta(\theta-1)\right)^{\frac{3}{2}}} .
$$

where $\mathrm{u}$ and $\mathrm{v} \in \mathrm{I}$, and $\theta \in[0, \infty]$ is a dependence parameter.

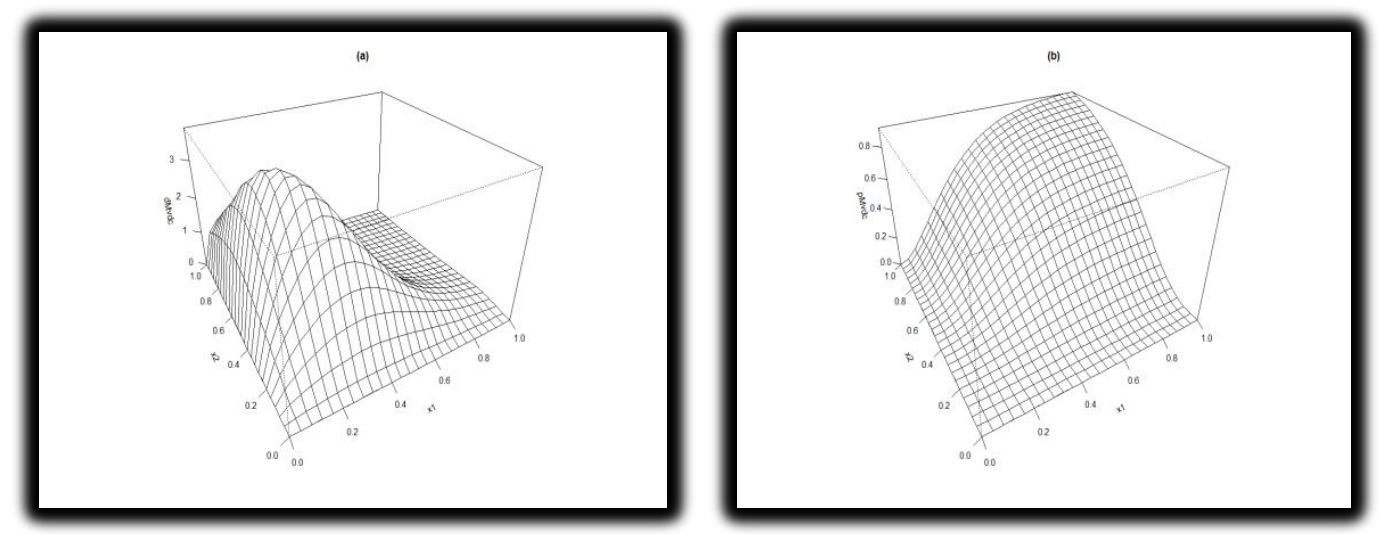

Figure (5): Plots the PDF and Cdf of the BBE based on Plackett copula

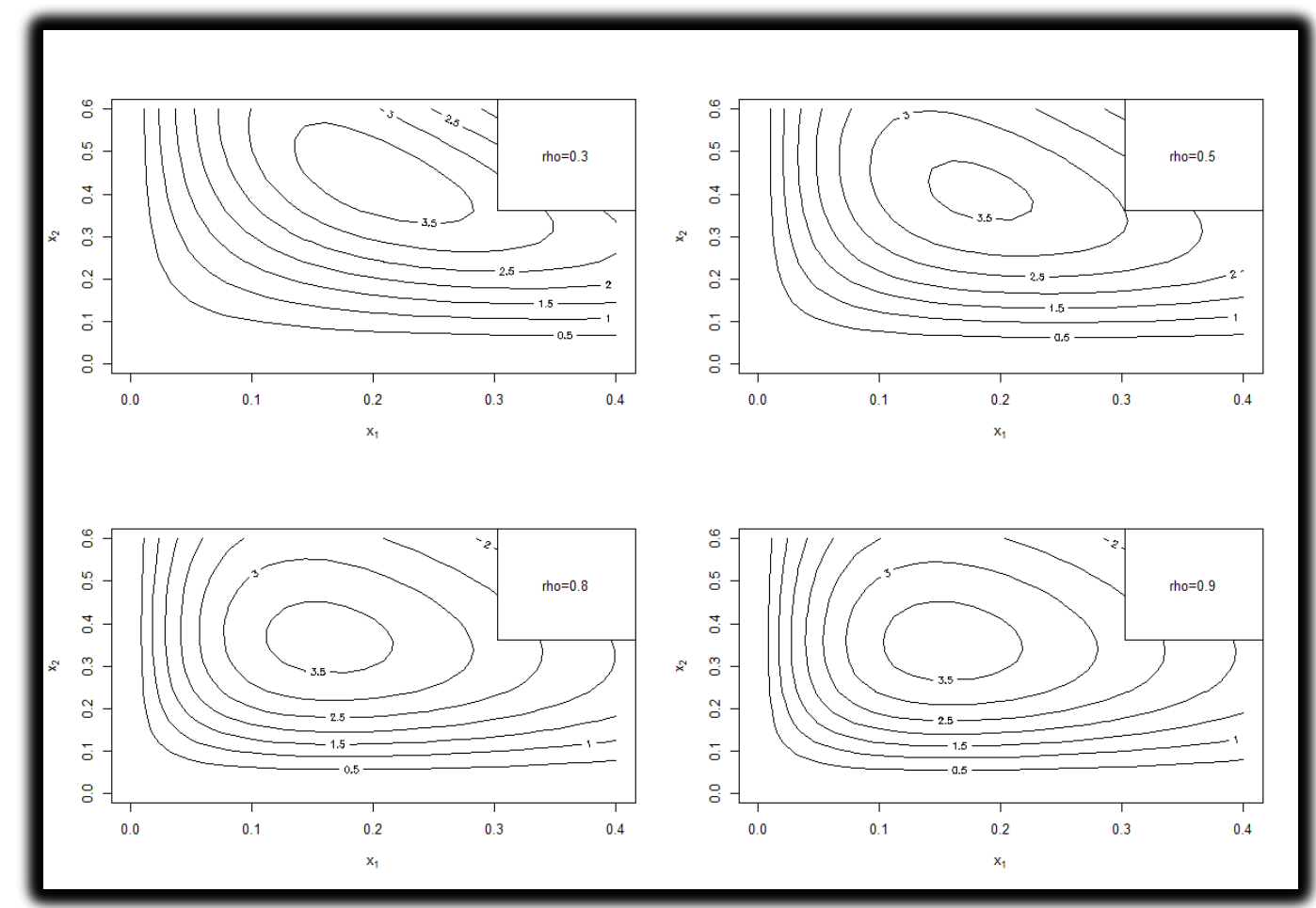

Figure (6): Contour plots of BBEbased on Plackett copula for different values of $\theta$.

\section{Parameters Estimation}

In this section, we provide the estimation of the unknown parameters of BBE distributions by two approaches to fitting copula models. Parametric and semiparametric are methods used to estimate proposed distribution parameters.

\subsection{Parametric methods of estimation:}

There are two approaches to fitting copula models. The first one approach is two steps procedure estimating the marginal and the copula parameter separately. The second approach is two steps procedure estimating the marginal and the copula parameter, which is computed from the pseudo-observations separately. 


\section{Maximum likelihood estimation (ML)}

We provide the estimation of the unknown parameters of BBE distributions by the approach maximum likelihood. By using the two-step estimation (ML). The approach is two steps procedure estimating the marginal and the copula parameter separately.

The log-likelihood function expressed as

$$
\log L=\sum_{i=1}^{n}\left[\log f_{1}\left(x_{1 i}\right)+\log f_{2}\left(x_{2 i}\right)+\log c\left(F_{1}\left(x_{1 i}\right), F_{2}\left(x_{2 i}\right)\right)\right]
$$

The log-likelihood function in (16) can be re-expressed as

$$
\left.\log L=\sum_{i=1}^{n} \log f_{1}\left(x_{1 i}\right)+\sum_{i=1}^{n} \log f_{2}\left(x_{2 i}\right)+\sum_{i=1}^{n} \log c\left(F_{1}\left(x_{1 i}\right), F_{2}\left(x_{2 i}\right)\right)\right]
$$

The first step is estimating the parameters of marginal distribution $F_{1}$ and $F_{2}$ by MLE separately as given,

$$
\log L_{j}=\sum_{i=1}^{n} \log f_{j}\left(x_{j i}\right), j=1,2 .
$$

Then, estimating copula parameters by maximizing the copula density as given

$\log L=\sum_{i=1}^{n} \log c\left(F_{1}\left(x_{1 i}\right), F_{2}\left(x_{2 i}\right)\right)$.

By considering the first step with (BE) distribution, the parameters of each marginal distribution will be estimated by MLE. If $x_{1}, \ldots, x_{n}$ is a random sample fromBE $\left(\alpha_{j}, a_{j}, b_{j}\right)$, then the log-likelihood function $L\left(\alpha_{j}, a_{j}, b_{j}\right)$ is

$\log L\left(x_{j}, \alpha_{j}, a_{j}, b_{j}\right)=$

$\log \left(\alpha_{j}\right)-\log \left(B\left(a_{j}, b_{j}\right)\right)-b_{j} \alpha_{j} x_{j}+$

$\left(a_{j}-\right.$

$1 \log 1-$

$\exp -\alpha j x j$

(20)

$\frac{\partial \log L\left(t_{j}, \alpha_{j}, a_{j}, b_{j}\right)}{\partial \alpha_{j}}=\frac{1}{\alpha_{j}}-\frac{b_{j}}{\alpha_{j}}\left(\alpha_{j} x_{j}\right)+\frac{\left(a_{j}-1\right)\left(\alpha_{j} x_{j}\right) \exp \left\{-\alpha_{j} x_{j}\right\}}{\alpha_{j}\left[1-\exp \left\{-\alpha_{j} x_{j}\right\}\right]}$,

$\frac{\partial \log L\left(t_{j}, \alpha_{j}, a_{j}, b_{j}\right)}{\partial a_{j}}=-\left\{\delta\left(a_{j}\right)-\delta\left(a_{j}+b_{j}\right)\right\}+\log \left[1-\exp \left\{-\alpha_{j} x_{j}\right\}\right]$,

and

$\frac{\partial \log L\left(t_{j}, \alpha_{j}, a_{j}, b_{j}\right)}{\partial b_{j}}=-\left\{\delta\left(b_{j}\right)-\delta\left(a_{j}+b_{j}\right)\right\}-\alpha_{j} x_{j}$

The solution of the system of nonlinear equations (21),(22)and (23) gives the MLEs of $\alpha_{j}, a_{j}$ and $b_{j}$.

The maximum likelihood estimates (MLEs)can be calculated by making equations (21),(22)and (23) equal to zero. These equations can be solved numerically for $\alpha_{j}, a_{j}$ and $b_{j}$. Wecanuseiterativetechniquessuch asaNewtonRaphsontypealgorithmtoobtaintheestimatesoftheseparameters.

Then copula density will estimated as given,

$$
\log L(\theta)=\sum_{i=1}^{n} \log c\left(\widehat{F}_{1}\left(x_{1 i}\right), \widehat{F}_{2}\left(x_{2 i}\right)\right),
$$

Where $\widehat{F}_{1}\left(x_{1}\right)$ and , $\widehat{F}_{2}\left(x_{2}\right)$ denote the ML estimates of the parameters from first step.

The solution of the nonlinear equation (24) gives the MLE of $\theta$.

\section{Modified maximum likelihood estimation (MML)}

This a new method is suggested in this article the first step is estimating the parameters of marginal distribution $F_{1}$ and $F_{2}$ by MLE separately as given,

$$
\log L_{j}=\sum_{i=1}^{n} \log f_{j}\left(x_{j i}\right), j=1,2 .
$$

The maximum likelihood estimates (MLEs) can be calculated by making equations (21),(22) and (23) equal to zero. These equations can be solved numerically for $\alpha_{j}, a_{j}$ and $b_{j}$. We can use iterative techniques such as a Newton-Raphson type algorithm to obtain the estimates of these parameters.

Second step is estimating copula parameters by maximizing the copula density as given

$$
\log L(\theta)=\sum_{i=1}^{n} \log \left[c_{\theta}\left(\widehat{U}_{i}, \widehat{V}_{i}\right)\right](25)
$$

Where $\widehat{U}_{i}, \widehat{\mathrm{V}}_{\mathrm{i}}$ are pseudo-observations computed from $\widehat{U}_{\mathrm{i}}=\frac{R_{1 i}}{n+1}=\frac{n}{n+1} \widehat{F}_{1}\left(t_{1 i}\right), \widehat{\mathrm{V}}_{\mathrm{i}}=\frac{R_{2 i}}{n+1}=\frac{n}{n+1} \widehat{F}_{1}\left(t_{2 i}\right)$, , $R 1 i, R 2 i$ are respectively the ranks of $t 1 i, t 2 i$.

It is important to respect that the margins Cdf.s are estimated parametrically from the first step.

\subsection{Semiparametric methods of estimation}

Two semiparametric methods to estimate the copula parameter in copula models are compared the two Methods-of-moments approaches of namely inversion Kendall's and inversion of Spearman's rho. 


\section{Methods-of-moments}

Method-of-moments approaches of inversion Kendall's and inversion of Spearman's rho

As it is mentioned in Kojadinovic and Yan (2010), let c be a bivariate random sample from $\operatorname{Cdf} C_{\theta}\left[F_{1}\left(t_{1}\right), F_{2}\left(t_{2}\right)\right]$, where $\mathrm{F}_{1}$ and $\mathrm{F}_{2}$ are continuous Cdf.s and $C_{\theta}$ is an absolutely continuous copula such that $\theta \in \mathcal{O}$, where $\mathcal{O}$ is an open subset of $R^{2}$. Furthermore, let $R_{1}, \ldots, R_{n}$ are the vectors of ranks associated with $t_{1}, \ldots, t_{n}$ unless otherwise stated. In what follows, all vectors are row vectors. Method-of-moments approaches are based on the inversion of a consistent estimator of a moment of the copula $C_{\theta}$. The two best-known moments, Spearman's rho and Kendall's tau, are respectively given by

$$
\rho(\theta)=12 \int_{[0,1]^{2}} u_{v d C}(u, v)-3
$$

and

$$
\tau(\theta)=4 \int_{[0,1]^{2}} C_{\theta}(u, v) d_{\theta}(u, v)-1 .
$$

Consistent estimators of these two moments can be expressed as

$\rho_{n}=\frac{12}{n(n+1)(n-1)} \sum_{i=1}^{n} R_{i, 1} R_{i, 2}-3 \frac{n+1}{n-1}$,

And

$$
\tau_{n}=\frac{4}{n(n-1)} \sum_{i=1}^{n} 1\left[t_{i, 1} \leq t_{j, 1}\right] 1\left[t_{i, 2} \leq t_{j, 2}\right]-1 .
$$

When the functions $\rho$ and $\tau$ are one-to-one, consistent estimators of $\theta$ are given by $\theta_{n, \rho}=\rho^{-1}\left(\rho_{n}\right)$,

$$
\theta_{n, \tau}=\tau^{-1}\left(\tau_{n}\right)
$$

It can be called inversion of Kendall's (itau) and inversion of Spearman's rho (irho) respectively. For more information, see Kojadinovic and Yan (2010).

As explained above the methods-of-moments (itau) and (irho) estimation method for copula is considered as a semiparametric method of estimation.

\section{Goodness Of Fit Tests For Copula}

The idea of this test is to compare the empirical copula with the parametric estimator derived under the null hypothesis see Dobrić and Schmid(2007) and Fermanian(2005). That is, test if C is well-represented by a specific copula $C_{\theta}$

$$
H_{0}: C=C_{\theta} \quad \text { Vs. } \quad H_{1}: C \neq C_{\theta}
$$

Two approaches are commonly used in the literature to test the goodness of fit of a copula; the parametric bootstrap see Genest and Rémillard (2008)or the fast multiplier approach see Genest, et al. ( 2009), and Kojadinovicet al. ( 2011). The goodness of fit tests based on the empirical process

$\mathbb{C}_{n}(u, v)=\sqrt{n}\left\{C_{n}(u, v)-C_{\theta_{n}}(u, v)\right\}$,

where $C_{n}(u, v)$ is the empirical copula of the data of $T_{1}$ and $T_{2}$

$$
C_{n}(u, v)=\frac{1}{n} \sum_{i=1}^{n} 1\left(U_{i, n} \leq u, V_{i, n} \leq v\right), u, v \in[0,1],
$$

$U_{i, n}, V_{i, n}$ are pseudo observations from $\mathrm{C}$ calculated from data as follows

$U_{i, n}=\frac{R_{1 i}}{n+1}, V_{i, n}=\frac{R_{2 i}}{n+1}, \quad R_{1 i}, R_{2 i}$ are respectively the ranks of $t_{1 i}, t_{2 i}$.

Here $C_{n}(u, v)$ is a consistent estimator and $\theta_{n}$ is an estimator of $\theta$ obtained using the pseudo observations. According to Genest et al.(2009), the test statistics is the Cramer-von Miss and is defined as

$$
S_{n}=\sum_{i=1}^{n}\left\{C_{n}\left(U_{i, n}, V_{i, n}\right)-C_{\theta_{n}}\left(U_{i, n}, V_{i, n}\right)\right\}^{2}
$$

See for details Genest et al., (2009), Genest and Rémillard, (2008) and Kojadinovic et al., (2011).

\section{Simulation Data}

In this section, a comparison between the three proposed models via different types of copulas is presented. The correlation measures Kendall's tau and Spearman's rho of two variables with BBE distribution are obtained and used to provide the values of copula parameters.

Considering the following values of marginal and copula parameters of BBE distribution based on Gaussian, FGM and Plackett copulas with different sizes of sample $(n=20,30,50,100,150$ and 200):

$\mathrm{a}_{1}=2, \mathrm{~b}_{1}=12, \alpha_{1}=2, \mathrm{a}_{2}=3, \mathrm{~b}_{2}=6, \alpha_{2}=2$ Gaussiancopula parameter $\theta_{G}=0.8, \quad$ FGM copula parameter $\theta_{F}=0.3$ and Plackett copula parameter $\theta_{p}=0.3$. 
The estimates for these parameters of three models by different three types of copulas and the corresponding bias, mean squared errors and relative mean squared errors based on 1000 replications are reported in Table 1, 2, $3,4,5$, and 6 .

Table 1. The estimates, the bias, the mean squared errors and the relative mean squared errors of parameters by simulation study for BBE distribution based Gaussian copula

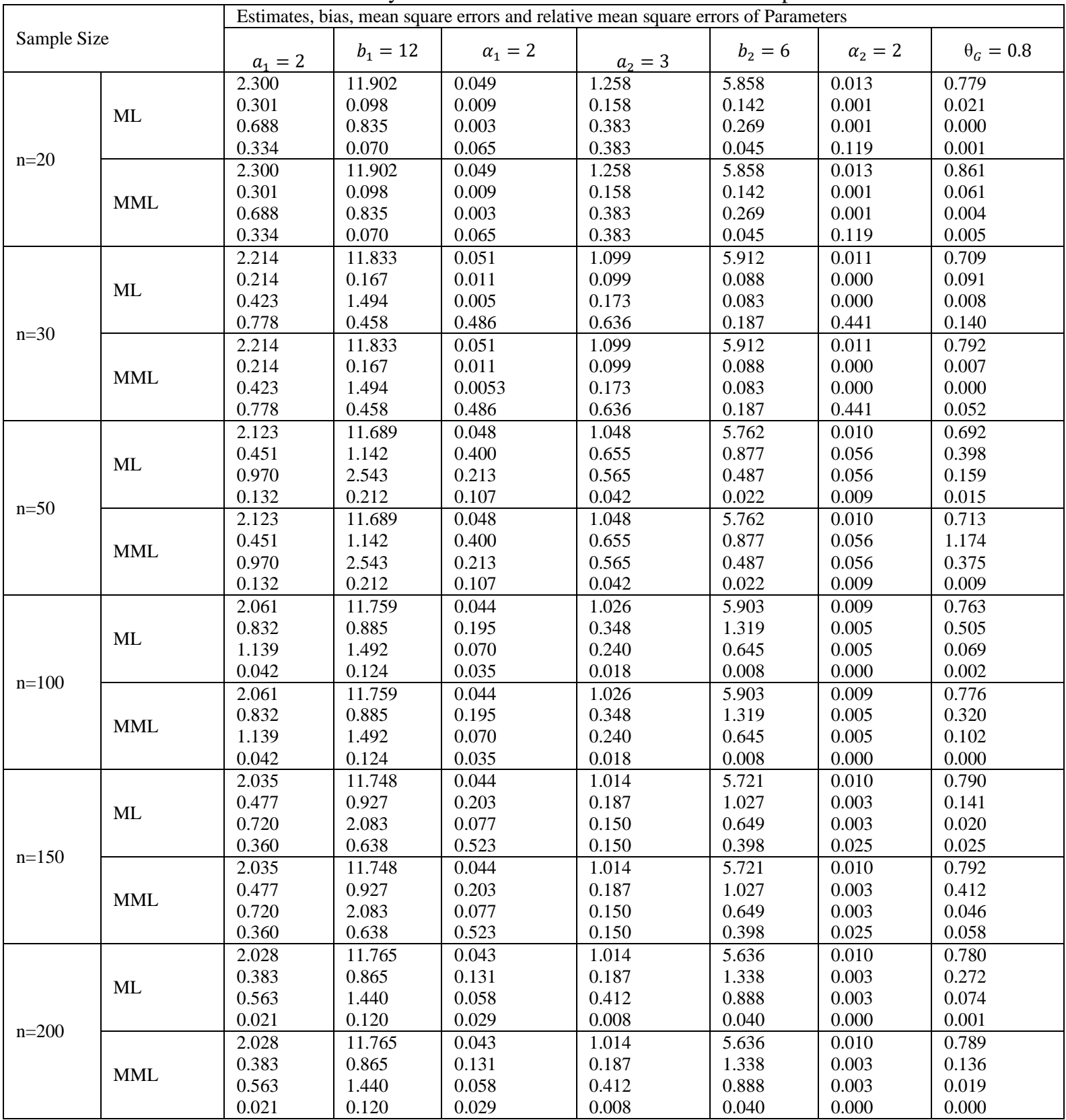

Table 2. The estimates, the bias, the mean squared errors and the relative mean squared errors of parameters of correlation parameter by simulation study for BBE distribution based Gaussian copula

\begin{tabular}{|l|l|l|l|l|l|}
\hline \multirow{2}{*}{ Sample Size } & \multicolumn{5}{|c|}{$\theta_{G}=0.8$} \\
\cline { 2 - 6 } & Estimates & bias & MSE & RMSE & Method Estimation \\
\hline \multirow{5}{*}{$\mathrm{n}=20$} & 0.779 & 0.021 & 0.000 & 0.001 & ML \\
& 0.861 & 0.061 & 0.004 & 0.005 & MML \\
& 0.855 & 0.055 & 0.003 & 0.004 & Itau \\
& 0.856 & 0.056 & 0.003 & 0.004 & IRho \\
$\mathrm{n}=30$ & 0.709 & 0.091 & 0.008 & 0.140 & ML \\
& 0.792 & 0.007 & 0.000 & 0.052 & MML \\
& 0.778 & 0.022 & 0.000 & 0.108 & Itau \\
& 0.780 & 0.019 & 0.000 & 0.088 & IRho \\
\hline
\end{tabular}


Bivariate Beta Exponential Distributions

\begin{tabular}{|l|l|l|l|l|l|}
\hline & 0.692 & 0.398 & 0.159 & 0.015 & ML \\
$\mathrm{n}=50$ & 0.713 & 1.174 & 0.375 & 0.009 & MML \\
& 0.680 & 0.442 & 0.195 & 0.018 & Itau \\
\hline \multirow{5}{*}{$\mathrm{n}=100$} & 0.668 & 0.487 & 0.327 & 0.022 & IRho \\
& 0.763 & 0.505 & 0.069 & 0.002 & ML \\
& 0.776 & 0.320 & 0.102 & 0.000 & MML \\
& 0.749 & 0.695 & 0.131 & 0.003 & Itau \\
$\mathrm{n}=150$ & 0.742 & 0.788 & 0.169 & 0.004 & IRho \\
& 0.790 & 0.141 & 0.020 & 0.025 & ML \\
& 0.792 & 0.412 & 0.046 & 0.058 & MML \\
& 0.782 & 0.249 & 0.062 & 0.062 & Itau \\
$\mathrm{n}=200$ & 0.780 & 0.273 & 0.074 & 0.093 & IRho \\
& 0.780 & 0.272 & 0.074 & 0.001 & ML \\
& 0.789 & 0.136 & 0.019 & 0.000 & MML \\
& 0.786 & 0.183 & 0.034 & 0.000 & Itau \\
& 0.783 & 0.224 & 0.050 & 0.000 & IRho \\
\hline
\end{tabular}

Table 3. The estimates, the bias, the mean squared errors and the relative mean squared errors of parameters by simulation study for BBE distribution based FGM copula

\begin{tabular}{|c|c|c|c|c|c|c|c|c|}
\hline \multirow{2}{*}{\multicolumn{2}{|c|}{ Sample Size }} & \multicolumn{7}{|c|}{ Estimates ,bias, mean square errors and relative mean square errors of Parameters } \\
\hline & & $a_{1}=2$ & $b_{1}=12$ & $\alpha_{1}=2$ & $a_{2}=3$ & $b_{2}=6$ & $\alpha_{2}=2$ & $\theta_{F}=0.3$ \\
\hline \multirow{8}{*}{$\mathrm{n}=20$} & \multirow{4}{*}{ ML } & 2.364 & 11.924 & 0.050 & 1.161 & 5.868 & 0.012 & 0.503 \\
\hline & & 0.364 & 0.076 & 0.010 & 0.161 & 0.132 & 0.000 & 0.203 \\
\hline & & 1.245 & 0.798 & 0.005 & 0.258 & 0.188 & 0.000 & 0.041 \\
\hline & & 0.623 & 0.066 & 0.113 & 0.258 & 0.0312 & 0.067 & 0.137 \\
\hline & \multirow{4}{*}{ MML } & 2.364 & 11.924 & 0.050 & 1.161 & 5.868 & 0.012 & 0.523 \\
\hline & & 0.364 & 0.076 & 0.010 & 0.161 & 0.132 & 0.000 & 0.223 \\
\hline & & 1.245 & 0.798 & 0.005 & 0.258 & 0.188 & 0.000 & 0.050 \\
\hline & & 0.623 & 0.066 & 0.113 & 0.258 & 0.0312 & 0.067 & 0.166 \\
\hline \multirow{8}{*}{$\mathrm{n}=30$} & \multirow{4}{*}{ ML } & 2.207 & 11.804 & 0.050 & 1.115 & 5.917 & 0.011 & 0.034 \\
\hline & & 0.207 & 0.195 & 0.010 & 0.115 & 0.083 & 0.001 & 0.004 \\
\hline & & 0.526 & 1.823 & 0.005 & 0.240 & 0.149 & 0.001 & 0.000 \\
\hline & & 0.263 & 0.152 & 0.120 & 0.240 & 0.025 & 0.056 & 0.001 \\
\hline & \multirow{4}{*}{ MML } & 2.207 & 11.804 & 0.050 & 1.115 & 5.917 & 0.011 & 0.188 \\
\hline & & 0.207 & 0.195 & 0.010 & 0.115 & 0.083 & 0.001 & 0.158 \\
\hline & & 0.526 & 1.823 & 0.005 & 0.240 & 0.149 & 0.001 & 0.025 \\
\hline & & 0.263 & 0.152 & 0.120 & 0.240 & 0.025 & 0.056 & 0.834 \\
\hline \multirow{8}{*}{$\mathrm{n}=50$} & \multirow{4}{*}{ ML } & 2.113 & 11.734 & 0.048 & 1.066 & 5.771 & 0.010 & 0.328 \\
\hline & & 0.113 & 0.266 & 0.008 & 0.066 & 0.229 & 0.000 & 0.028 \\
\hline & & 0.203 & 2.145 & 0.005 & 0.049 & 0.123 & 0.000 & 0.001 \\
\hline & & 0.101 & 0.179 & 0.120 & 0.049 & 0.021 & 0.013 & 0.003 \\
\hline & \multirow{4}{*}{ MML } & 2.113 & 11.734 & 0.048 & 1.066 & 5.771 & 0.010 & 0.366 \\
\hline & & 0.113 & 0.266 & 0.008 & 0.066 & 0.229 & 0.000 & 0.066 \\
\hline & & 0.203 & 2.145 & 0.005 & 0.049 & 0.123 & 0.000 & 0.004 \\
\hline & & 0.101 & 0.179 & 0.120 & 0.049 & 0.021 & 0.013 & 0.014 \\
\hline \multirow{8}{*}{$\mathrm{n}=100$} & \multirow{4}{*}{ ML } & 2.050 & 11.804 & 0.043 & 1.031 & 5.890 & 0.010 & 0.265 \\
\hline & & 0.679 & 0.720 & 0.140 & 0.416 & 0.405 & 0.005 & 0.480 \\
\hline & & 1.086 & 1.049 & 0.060 & 0.253 & 0.796 & 0.005 & 0.063 \\
\hline & & 0.040 & 0.087 & 0.030 & 0.019 & 0.010 & 0.000 & 0.004 \\
\hline & \multirow{4}{*}{ MML } & 2.050 & 11.804 & 0.043 & 1.031 & 5.890 & 0.010 & 0.331 \\
\hline & & 0.679 & 0.720 & 0.140 & 0.416 & 0.405 & 0.005 & 0.423 \\
\hline & & 1.086 & 1.049 & 0.060 & 0.253 & 0.796 & 0.005 & 0.179 \\
\hline & & 0.040 & 0.087 & 0.030 & 0.019 & 0.010 & 0.000 & 0.003 \\
\hline \multirow{8}{*}{$\mathrm{n}=150$} & \multirow{4}{*}{ ML } & 2.036 & 11.852 & 0.042 & 1.022 & 5.750 & 0.010 & 0.083 \\
\hline & & 0.486 & 0.543 & 0.121 & 0.309 & 0.921 & 0.003 & 0.799 \\
\hline & & 0.702 & 1.163 & 0.058 & 0.167 & 0.549 & 0.003 & 0.639 \\
\hline & & 0.026 & 0.097 & 0.029 & 0.012 & 0.025 & 0.000 & 0.157 \\
\hline & \multirow{4}{*}{ MML } & 2.036 & 11.852 & 0.042 & 1.022 & 5.750 & 0.010 & 0.130 \\
\hline & & 0.486 & 0.543 & 0.121 & 0.309 & 0.921 & 0.003 & 0.625 \\
\hline & & 0.702 & 1.163 & 0.058 & 0.167 & 0.549 & 0.003 & 0.391 \\
\hline & & 0.026 & 0.097 & 0.029 & 0.012 & 0.025 & 0.000 & 0.096 \\
\hline \multirow{8}{*}{$\mathrm{n}=200$} & \multirow{4}{*}{ ML } & 2.026 & 11.827 & 0.042 & 1.020 & 5.672 & 0.010 & 0.193 \\
\hline & & 0.351 & 0.638 & 0.081 & 0.269 & 1.207 & 0.003 & 0.395 \\
\hline & & 0.520 & 2.891 & 0.050 & 0.434 & 0.726 & 0.003 & 0.156 \\
\hline & & 0.019 & 0.065 & 0.025 & 0.009 & 0.033 & 0.000 & 0.038 \\
\hline & \multirow{4}{*}{ MML } & 2.026 & 11.827 & 0.042 & 1.020 & 5.672 & 0.010 & 0.234 \\
\hline & & 0.351 & 0.638 & 0.081 & 0.269 & 1.207 & 0.003 & 0.89 \\
\hline & & 0.520 & 2.891 & 0.050 & 0.434 & 0.726 & 0.003 & 0.219 \\
\hline & & 0.019 & 0.065 & 0.025 & 0.009 & 0.033 & 0.000 & 0.015 \\
\hline
\end{tabular}


Table 4. The estimates, the bias, the mean squared errors and the relative mean squared errors of parameters of correlation parameter by simulation study for BBE distribution based FGM copula

\begin{tabular}{|c|c|c|c|c|c|}
\hline \multirow{2}{*}{ Sample Size } & \multicolumn{5}{|c|}{$\theta_{F}=0.3$} \\
\hline & Estimates & bias & $M S E$ & RMSE & Method Estimation \\
\hline \multirow{4}{*}{$\mathrm{n}=20$} & 0.503 & 0.203 & 0.041 & 0.137 & ML \\
\hline & 0.523 & 0.223 & 0.050 & 0.166 & MML \\
\hline & 0.331 & 0.032 & 0.001 & 0.003 & Itau \\
\hline & 0.402 & 0.101 & 0.010 & 0.034 & IRho \\
\hline \multirow{4}{*}{$\mathrm{n}=30$} & 0.034 & 0.004 & 0.000 & 0.001 & $\mathrm{ML}$ \\
\hline & 0.188 & 0.158 & 0.025 & 0.834 & MML \\
\hline & 0.155 & 0.125 & 0.016 & 0.522 & Itau \\
\hline & 0.139 & 0.109 & 0.012 & 0.400 & IRho \\
\hline \multirow{4}{*}{$\mathrm{n}=50$} & 0.328 & 0.028 & 0.001 & 0.003 & ML \\
\hline & 0.366 & 0.066 & 0.004 & 0.014 & MML \\
\hline & 0.246 & 0.054 & 0.003 & 0.010 & Itau \\
\hline & 0.310 & 0.010 & 0.000 & 0.000 & IRho \\
\hline \multirow{4}{*}{$\mathrm{n}=100$} & 0.265 & 0.480 & 0.063 & 0.004 & ML \\
\hline & 0.331 & 0.423 & 0.179 & 0.003 & MML \\
\hline & 0.290 & 0.453 & 0.056 & 0.000 & Itau \\
\hline & 0.319 & 0.258 & 0.067 & 0.001 & IRho \\
\hline \multirow{4}{*}{$\mathrm{n}=150$} & 0.083 & 0.799 & 0.639 & 0.157 & ML \\
\hline & 0.130 & 0.625 & 0.391 & 0.096 & MML \\
\hline & 0.105 & 0.717 & 0.514 & 0.127 & Itau \\
\hline & 0.124 & 0.648 & 0.420 & 0.103 & IRho \\
\hline \multirow{4}{*}{$\mathrm{n}=200$} & 0.193 & 0.395 & 0.156 & 0.038 & ML \\
\hline & 0.234 & 0.89 & 0.219 & 0.015 & MML \\
\hline & 0.213 & 1.177 & 0.377 & 0.025 & Itau \\
\hline & 0.225 & 1.013 & 0.279 & 0.019 & IRho \\
\hline
\end{tabular}

Table 5.The estimates, the bias, the mean squared errors and the relative mean squared errors of parameters by simulation study for BBE distribution based Plackett copula

\begin{tabular}{|c|c|c|c|c|c|c|c|c|}
\hline \multirow{2}{*}{\multicolumn{2}{|c|}{ Sample Size }} & \multicolumn{7}{|c|}{ Estimates ,bias, mean square errors and relative mean square errors of Parameter } \\
\hline & & $a_{1}=2$ & $b_{1}=2$ & $\alpha_{1}=2$ & $a_{2}=3$ & $b_{2}=2$ & $\alpha_{2}=2$ & $\theta_{p}=0.3$ \\
\hline \multirow{2}{*}{$\mathrm{n}=20$} & ML & $\begin{array}{l}2.373 \\
0.373 \\
1.203 \\
0.602\end{array}$ & $\begin{array}{l}11.897 \\
0.103 \\
1.025 \\
0.085\end{array}$ & $\begin{array}{l}0.053 \\
0.013 \\
0.006 \\
0.162\end{array}$ & $\begin{array}{l}1.173 \\
0.173 \\
0.413 \\
0.413\end{array}$ & $\begin{array}{l}5.859 \\
0.141 \\
0.214 \\
0.036\end{array}$ & $\begin{array}{l}0.012 \\
0.000 \\
0.001 \\
0.070\end{array}$ & $\begin{array}{l}0.129 \\
0.171 \\
0.029 \\
0.098\end{array}$ \\
\hline & MML & $\begin{array}{l}2.373 \\
0.373 \\
1.203 \\
0.602\end{array}$ & $\begin{array}{l}11.897 \\
0.103 \\
1.025 \\
0.085\end{array}$ & $\begin{array}{l}0.053 \\
0.013 \\
0.006 \\
0.162\end{array}$ & $\begin{array}{l}1.173 \\
0.173 \\
0.413 \\
0.413\end{array}$ & $\begin{array}{l}5.859 \\
0.141 \\
0.214 \\
0.036\end{array}$ & $\begin{array}{l}0.012 \\
0.000 \\
0.001 \\
0.070\end{array}$ & $\begin{array}{l}0.175 \\
0.125 \\
0.016 \\
0.052\end{array}$ \\
\hline \multirow{2}{*}{$\mathrm{n}=30$} & ML & $\begin{array}{l}2.219 \\
0.807 \\
1.521 \\
0.207\end{array}$ & $\begin{array}{l}11.793 \\
0.759 \\
1.576 \\
0.131\end{array}$ & $\begin{array}{l}0.050 \\
0.495 \\
0.198 \\
0.100\end{array}$ & $\begin{array}{l}1.095 \\
1.291 \\
1.145 \\
0.085\end{array}$ & $\begin{array}{l}5.916 \\
1.136 \\
0.801 \\
0.010\end{array}$ & $\begin{array}{l}0.010 \\
0.023 \\
1.258 \\
0.001\end{array}$ & $\begin{array}{l}0.449 \\
0.549 \\
0.301 \\
0.074\end{array}$ \\
\hline & MML & $\begin{array}{l}2.219 \\
0.807 \\
1.521 \\
0.207\end{array}$ & $\begin{array}{l}11.793 \\
0.759 \\
1.576 \\
0.131\end{array}$ & $\begin{array}{l}0.050 \\
0.495 \\
0.198 \\
0.100\end{array}$ & $\begin{array}{l}1.095 \\
1.291 \\
1.145 \\
0.085\end{array}$ & $\begin{array}{l}5.916 \\
1.136 \\
0.801 \\
0.010\end{array}$ & $\begin{array}{l}0.010 \\
0.023 \\
1.258 \\
0.001\end{array}$ & $\begin{array}{l}0.439 \\
0.511 \\
0.261 \\
0.064\end{array}$ \\
\hline \multirow{2}{*}{$\mathrm{n}=50$} & ML & $\begin{array}{l}2.129 \\
0.474 \\
0.830 \\
0.113 \\
\end{array}$ & $\begin{array}{l}11.736 \\
0.973 \\
0.250 \\
0.178\end{array}$ & $\begin{array}{l}0.049 \\
0.428 \\
2.130 \\
0.125\end{array}$ & $\begin{array}{l}1.060 \\
0.817 \\
0.250 \\
0.039\end{array}$ & $\begin{array}{l}5.782 \\
0.802 \\
1.187 \\
0.015\end{array}$ & $\begin{array}{l}0.010 \\
0.013 \\
0.013 \\
0.001\end{array}$ & $\begin{array}{l}0.468 \\
0.617 \\
0.380 \\
0.094\end{array}$ \\
\hline & MML & $\begin{array}{l}2.129 \\
0.474 \\
0.830 \\
0.113\end{array}$ & $\begin{array}{l}11.736 \\
0.973 \\
0.250 \\
0.178\end{array}$ & $\begin{array}{l}0.049 \\
0.428 \\
2.130 \\
0.125\end{array}$ & $\begin{array}{l}1.060 \\
0.817 \\
0.250 \\
0.039\end{array}$ & $\begin{array}{l}5.782 \\
0.802 \\
1.187 \\
0.015\end{array}$ & $\begin{array}{l}0.010 \\
0.013 \\
0.013 \\
0.001\end{array}$ & $\begin{array}{l}0.357 \\
0.775 \\
0.164 \\
0.011\end{array}$ \\
\hline \multirow{2}{*}{$\mathrm{n}=100$} & ML & $\begin{array}{l}2.063 \\
0.859 \\
1.094 \\
0.547\end{array}$ & $\begin{array}{l}11.802 \\
0.729 \\
1.188 \\
1.340\end{array}$ & $\begin{array}{l}0.043 \\
0.174 \\
0.066 \\
0.453\end{array}$ & $\begin{array}{l}1.024 \\
0.331 \\
0.248 \\
0.248\end{array}$ & $\begin{array}{l}5.900 \\
1.350 \\
0.695 \\
0.426\end{array}$ & $\begin{array}{l}0.009 \\
5.373 \\
5.373 \\
0.044\end{array}$ & $\begin{array}{l}0.303 \\
0.129 \\
0.017 \\
0.015\end{array}$ \\
\hline & MML & $\begin{array}{l}2.063 \\
0.859 \\
1.094 \\
0.547\end{array}$ & $\begin{array}{l}11.802 \\
0.729 \\
1.188 \\
1.340\end{array}$ & $\begin{array}{l}0.043 \\
0.174 \\
0.066 \\
0.453\end{array}$ & $\begin{array}{l}1.024 \\
0.331 \\
0.248 \\
0.248\end{array}$ & $\begin{array}{l}5.900 \\
1.350 \\
0.695 \\
0.426\end{array}$ & $\begin{array}{l}0.009 \\
5.373 \\
5.373 \\
0.044\end{array}$ & $\begin{array}{l}0.326 \\
0.351 \\
0.123 \\
0.111\end{array}$ \\
\hline $\mathrm{n}=150$ & ML & $\begin{array}{l}2.044 \\
0.596 \\
0.741\end{array}$ & $\begin{array}{l}11.774 \\
0.830 \\
1.906\end{array}$ & $\begin{array}{l}0.045 \\
0.232 \\
0.099\end{array}$ & $\begin{array}{l}1.019 \\
0.260 \\
0.153\end{array}$ & $\begin{array}{l}5.735 \\
0.975 \\
0.586\end{array}$ & $\begin{array}{l}0.010 \\
2.100 \\
2.100\end{array}$ & $\begin{array}{l}0.455 \\
0.571 \\
0.326\end{array}$ \\
\hline
\end{tabular}


Bivariate Beta Exponential Distributions

\begin{tabular}{|l|l|l|l|l|l|l|l|l|}
\hline & & 0.027 & 0.159 & 0.050 & 0.011 & 0.027 & 0.000 & 0.080 \\
& & & & & & & & \\
\cline { 2 - 9 } & \multirow{3}{*}{ MML } & 2.044 & 11.774 & 0.045 & 1.019 & 5.735 & 0.010 & 0.406 \\
& 0.596 & 0.830 & 0.232 & 0.260 & 0.975 & 2.100 & 0.389 \\
& 0.741 & 1.906 & 0.099 & 0.153 & 0.586 & 2.100 & 0.151 \\
& & 0.027 & 0.159 & 0.050 & 0.011 & 0.027 & 0.000 & 0.037 \\
\hline \multirow{5}{*}{$\mathrm{n}=200$} & \multirow{3}{*}{ ML } & 2.030 & 11.704 & 0.044 & 1.019 & 5.647 & 0.010 & 0.461 \\
& & 0.400 & 1.090 & 0.198 & 0.262 & 1.297 & 3.225 & 0.593 \\
& & 0.551 & 1.970 & 0.074 & 0.406 & 0.877 & 3.295 & 0.601 \\
& & 0.020 & 0.164 & 0.037 & 0.008 & 0.040 & 0.000 & 0.087 \\
& \multirow{2}{*}{ MML } & 2.030 & 11.704 & 0.044 & 1.019 & 5.647 & 0.010 & 0.456 \\
& & 0.400 & 1.090 & 0.198 & 0.262 & 1.297 & 3.225 & 0.573 \\
& 0.551 & 1.970 & 0.074 & 0.406 & 0.877 & 3.295 & 0.329 \\
\hline
\end{tabular}

Table 6. The estimates, the bias, the mean squared errors and the relative mean squared errors of correlation parameter by simulation study for BBE distribution based Plackett copula

\begin{tabular}{|c|c|c|c|c|c|}
\hline \multirow{2}{*}{ Sample Size } & \multicolumn{5}{|c|}{$\theta_{p}=0.3$} \\
\hline & Estimates & bias & $M S E$ & RMSE & Method Estimation \\
\hline \multirow{4}{*}{$\mathrm{n}=20$} & 0.129 & 0.171 & 0.029 & 0.098 & $\mathrm{ML}$ \\
\hline & 0.175 & 0.125 & 0.016 & 0.052 & MML \\
\hline & 0.129 & 0.171 & 0.029 & 0.098 & Itau \\
\hline & 0.154 & 0.146 & 0.021 & 0.071 & IRho \\
\hline \multirow{4}{*}{$\mathrm{n}=30$} & 0.449 & 0.549 & 0.301 & 0.074 & ML \\
\hline & 0.439 & 0.511 & 0.261 & 0.064 & MML \\
\hline & 0.403 & 0.380 & 0.145 & 0.036 & Itau \\
\hline & 0.419 & 0.438 & 0.199 & 0.047 & IRho \\
\hline \multirow{4}{*}{$\mathrm{n}=50$} & 0.468 & 0.617 & 0.380 & 0.094 & ML \\
\hline & 0.357 & 0.775 & 0.164 & 0.011 & MML \\
\hline & 0.340 & 0.546 & 0.081 & 0.005 & Itau \\
\hline & 0.353 & 0.717 & 0.140 & 0.009 & IRho \\
\hline \multirow{4}{*}{$\mathrm{n}=100$} & 0.303 & 0.129 & 0.017 & 0.015 & ML \\
\hline & 0.326 & 0.351 & 0.123 & 0.111 & MML \\
\hline & 0.331 & 0.429 & 0.178 & 0.161 & Itau \\
\hline & 0.339 & 0.529 & 0.076 & 0.253 & IRho \\
\hline \multirow{4}{*}{$\mathrm{n}=150$} & 0.455 & 0.571 & 0.326 & 0.037 & ML \\
\hline & 0.406 & 0.389 & 0.151 & 0.080 & MML \\
\hline & 0.425 & 0.462 & 0.213 & 0.052 & Itau \\
\hline & 0.434 & 0.495 & 0.245 & 0.060 & IRho \\
\hline \multirow{4}{*}{$\mathrm{n}=200$} & 0.461 & 0.593 & 0.601 & 0.087 & $\mathrm{ML}$ \\
\hline & 0.456 & 0.573 & 0.329 & 0.081 & MML \\
\hline & 0.460 & 0.590 & 0.347 & 0.086 & Itau \\
\hline & 0.465 & 0.608 & 0.369 & 0.091 & IRho \\
\hline
\end{tabular}

From the results in Table 1,2, 3, 4, 5, and 6 we observed that

1. As expected, most results improve with increases in sample size.

2. For most selected values of $a_{1}, b_{1}, \alpha_{1}, a_{2}, b_{2}, \alpha_{2}$ and $\theta$ the bias, MSE and RMSE of the estimates $\hat{a}_{1}, \hat{b}_{1}, \hat{\alpha}_{1}, \hat{a}_{2}, \hat{b}_{2}, \hat{\alpha}_{2}$ and $\hat{\theta}$ become smaller as the sample size increases.

3. For $a_{2}$ greater than $a_{1}$, the most results $\hat{a}_{1}$ for are generally better than $\hat{a}_{2}$ for Furthermore, the values of $\hat{a}_{1}$ get better more rapidly than the values of $\hat{a}_{2}$ as the sample size increases.

4. For $b_{2}$ greater than $b_{1}$, the most results $\hat{b}_{1}$ for are generally better than $\hat{b}_{2}$ for Furthermore, the values of $\hat{b}_{1}$ get better more rapidly than the values of $\hat{b}_{2}$ as the sample size increases.

5. the efficient estimators of marginal parameters of three models differ according to the parameters. It seems that ML estimates $\hat{a}_{1}, \hat{b}_{1}, \hat{\alpha}_{1}, \hat{a}_{2}, \hat{b}_{2}, \hat{\alpha}_{2}$ and of three models are the same corresponding MML estimates.

6. For copula parameter, the MML provided efficient most estimates for Gaussian, FGM, and Plackett copula parameters compared to ML, Itau, and Irho. It is also noted that the ML and MML estimates for all copula parameters are close.

7. For copula parameter, it is observed that most estimates of Gaussian copula parameter $\theta_{G}$ were more efficient than the corresponding the estimates of copula parameterFGM $\theta_{F}$ and Plackett copula parameter $\theta_{p}$.

To check if the selected parmetric copula functions are suitable for the marginals, goodness of fit test statisticsusing selected copula functions for the marginals is preformed.The results in Table (7) show a non signficant p-value obtained using parmetric bootstrap for all copula functions which indicate that selected 
parmetric copula functions provide approporiate fit to the marginals. In addition, estimate of the copula parmeter based on ML, MML, Itau, and Irho methods for the gussian, FGM, and Plackett copulas . This estimatesare used as intial value when fitting these copula models using BE marginals.

Table 7. Goodness of fit test statistics with their p-values and estimate of the copula parameter for selected copula functions.

\begin{tabular}{|c|c|c|c|c|}
\hline $\begin{array}{l}\text { Copula } \\
\text { Function }\end{array}$ & statistic & p-value & Estimate of copula parameter $\theta$ & Method estimation \\
\hline \multirow[t]{4}{*}{ Gaussian } & 0.0139 & 0.6179 & 0.7986 & Ml \\
\hline & 0.0139 & 0.6578 & 0.7986 & MML \\
\hline & 0.0154 & 0.5679 & 0.7816 & Itau \\
\hline & 0.0157 & 0.5809 & 0.7799 & Irho \\
\hline \multirow[t]{4}{*}{ FGM } & 0.0113 & 0.9915 & 0.1318 & Ml \\
\hline & 0.0113 & 0.9905 & 0.1318 & MML \\
\hline & 0.0119 & 0.9885 & 0.1051 & Itau \\
\hline & 0.0115 & 0.9915 & 0.1239 & Irho \\
\hline \multirow[t]{4}{*}{ Plackett } & 0.0279 & 0.2003 & 0.4016 & Ml \\
\hline & 0.0279 & 0.1923 & 0.4016 & MML \\
\hline & 0.0241 & 0.2882 & 0.4255 & Itau \\
\hline & 0.0229 & 0.3601 & 0.4344 & Irho \\
\hline
\end{tabular}

\section{Acknowledgments}

The author would like to thank the Editor-in-Chief, and the referee for constructive comments, which greatly improved the paper.

\section{References}

[1]. Abd Elaal, M. K. Adham, S. A., and Malaka, H. M. (2017). Goodness of fit tests for some copulas an application for gene data. Advances and Applications in Statistical Sciences accepted.

[2]. Abd Elaal, M. K., Mahmoud,M. R., El-Gohary, M.M., and Baharth,L.A. (2016). Univariate and bivariate Burr Type X distributions based on mixtures and copula. International Journal of Mathematics and Statistics, 17(1),113-127.

[3]. Adham, S. A., Abd Elaal, M. K., and Malaka, H. M. (2016). Gaussian copula regression application. Journal International Mathematical Forum,11, 1053-1065.

[4]. Adham, S. A., and Walker, S. G. (2001). A multivariate Gompertz-type distribution. Journal of Applied Statistics, 28(8), 10511065 .

[5]. Adham, S. A., AL-Dayian, G. R., El Beltagy, S. H., and Abd Elaal, M. K. (2009). Bivariate half- logistic-type distribution. Academy of Business Journal, AL-Azhar University, 2, 92-107.

[6]. Alexander, C., Cordeiro, G.M., Ortega, E.M., and Sarabia, J.M. (2012). Generalized beta generated distributions. Computational Statistics and Data Analysis, 56, 1880-1897.

[7]. Akinsete A., Famoye F., Lee, C. (2008). The beta-Pareto distribution. Statistics 42(6), 547-563.

[8]. Aljarrah, M.A., Lee, C. and Famoye, F. (2014).On generating T-X family of distributions using quantile functions, Journal of Statistical Distributions and Applications 1, Article 2,

[9]. Alzaatreh, A., Lee, C., and Famoye, F. (2013). A new method for generating Families of continuous distributions. Metron, 71, 6379. doi:10.1007/s40300-013-0007-y.

[10]. Ateya, S. F., and Al-Alazwari, A. A. (2013). A new multivariate generalized exponential distribution with application. Far East Journal of Theoretical Statistics, 45(1), 51.

[11]. Azzalini, A. (1985). A class of distributions, which includes the normal ones. Scandinavian Journal of Statistics, 12, 171-178.

[12]. Cordeiro, G.M., Gomes, A.E., da-Silva, C.Q., and Ortega, E.M. (2013). The beta exponentiated Weibull distribution. Journal of statistical computation and simulation, 83(1),114-138.

[13]. Cordeiro, G.M., Silva, G.O. and Ortega, E.M.(2012).The beta extended Weibull distribution, Journal of Probability and Statistical Science (Taiwan), 10, 15-40.

[14]. Dobrić, J., and Schmid, F. (2007). A goodness of fit test for copulas based on Rosenblatt's transformation. Computational Statistics and Data Analysis, 51(9), 4633-4642. http://doi.org/10.1016/j.csda.2006.08.012

[15]. Eugene, N., Lee, C. and Famoye, F. (2002). Beta-normal distribution and its applications, Communications in Statistics-Theory and Methods, 31, 497-512.

[16]. Famoye, f., lee, c. and olumolade, o. (2005). The beta-weibull distribution. Journal of Statistical Theory and Applications, 4, 121136.

[17]. Fermanian, J.D. (2005). Goodness-of-fit tests for copulas. Journal of Multivariate Analysis, 95(1), $119-152$. http://doi.org/10.1016/j.jmva.2004.07.004

[18]. Genest, C., Ghoudi, K., and Rivest L. P., (1995). A semiparametric estimation procedure of dependence parameters in multivariate families of distributions,Biometrika, 82( 3), 543-552.

[19]. Genest, C., and Rémillard, B. (2008). Validity of the parametric bootstrap for goodness-of-fittesting in semiparametric models. In Annales de l'IHP Probabilit $\{$ é $\}$ s et statistiques, 44, 1096-1127.

[20]. Genest, C., Rémillard, B., \& Beaudoin, D. (2009). Goodness-of-fit tests for copulas: A review and a power study. Insurance: Mathematics and Economics, 44(2), 199-213.

[21]. Kojadinovic, I., and Yan, J. (2010). Comparison of three semiparametric methods for estimating dependence parameters in copula models,Insurance: Mathematics and Economics,47( 1), 52-63.

[22]. Kojadinovic, I., Yan, J., and Holmes, M. (2011). Fast large-sample goodness-of-fit tests for copulas. Statistica Sinica, $21(2), 841$.

[23]. Jones,M. C. (2004). Families of distributions arising from distributions of order statistics (with discussion). Test, 13, 1-43.

[24]. Kundu, D., Balakrishnan, N., and Jamalizadeh, A. (2010). Bivariate Birnbaum--Saunders distribution and associated inference. Journal of Multivariate Analysis, 101(1), 113-125.

[25]. Kundu, D., and Gupta, R. D. (2009). Bivariate generalized exponential distribution. Journal of Multivariate Analysis, 100(4), 581- 
593.

[26]. Kundu, D., and Gupta, R. D. (2011). Absolute continuous bivariate generalized exponential distribution. AStA Advances in Statistical Analysis, 95(2), 169-185.

[27]. Merovci, F., Khaleel, M.A., and Ibrahim, N.A.(2016). The beta Burr type X distribution properties with application. SpringerPlus, 5-697. DOI 10.1186/s40064-016-2271-9

[28]. Merovci, F., and Sharma, V.K.(2014).The beta-lindley distribution: properties and applications.Journal of Applied Mathematics,101989511-198951.

[29]. Nadarajah, S., Cordeiro, G.M. and Ortega, E.M.(2015).The Zografos-Balakrishnan-G family of distributions: Mathematical properties and applications.Communications in Statistics- Theory and Methods, 44, 186-215.

[30]. Nadarajah, S., and Kotz. S. (2004).The beta Gumbel distribution. Mathematical Problems in Engineering, 10, $323-332$.

[31]. Nadarajah,S., and Kotz. S. (2006).The beta exponential distribution. Reliability Engineering and System Safety, 91, 689-697.

[32]. Nadarajah, S., and Rocha, R. (2016 a).Newdistns: An R Package for New Families of Distributions, Journal of Statistical Software, 69(10), 1-32, doi:10.18637/jss.v069.i10

[33]. Nadarajah, S., and Rocha, R. (2016 b). Newdistns: Computes PDF, CDF, Quantile and Random Numbers, Measures of Inference for 19 General Families of Distributions. R package version 2.1, URL https://CRAN.R-project.org/package=Newdistns.

[34]. Nelsen, R. B. (1999). An Introduction to Copulas. Springer\&Verla, New York. Inc.

[35]. Paranaíba, P.F., Ortega, E.M., Cordeiro, G.M., and Pescim, R.R. (2011) The beta Burr XII distribution with application to lifetime data. Computational Statistics and Data Analysis, 55(2),1118-1136.

[36]. Pescim, R.R., Demétrio, C.G., Cordeiro, G.M., Ortega, E.M., and Urbano, M.R. (2010). The beta generalized half-normal distribution. Computational Statistics and Data Analysis, 54, 945-957.

[37]. Sarabia,J.M., Prieto, F., and Jorda, V.,(2014). Bivariate beta-generated distributions with applications to well-being data. Journal of Statistical Distributions and Applications, 1-15.

[38]. Silva, G.O., Ortega, E. M.,and Cordeiro, G.M. (2010). The beta modified Weibull distribution. Lifetime Data Analysis, 16(3), 409430.

[39]. Trivedi, P. K., and Zimmer, D. M. (2005). Copula modeling: an introduction for practitioners. Foundations and Trends in Econometrics, 1(1), 1-111. 